\title{
The Effect of Seasons on Gill Net Selectivity
}

\author{
Adnan Ayaz ${ }^{1}$ (D), Uğur Altinağaç ${ }^{1}$, Alkan Öztekin ${ }^{1}$ (D), Uğur Özekinci ${ }^{1}$
}

Cite this article as: Adnan, A., Altinagac, U., Oztekink, A., Ozekinci, U. (2019). The effect of seasons on gill net selectivity. Aquatic Sciences and Engineering, 34(4), 116-121.

ORCID IDs of the authors: A.A. 0000-0003-4839-9244; U.A. 0000-0002-3638-9834; A.Ö. 0000-0003-3914-9788; U.Ö. 0000-0003-2207-0168;

${ }^{1}$ Canakkale Onsekiz Mart University, Faculty of Marine Science and Technology,

Canakkale, Turkey

Submitted:

11.06.2019

Revision Requested

03.09.2019

Last Revision Received 06.09.2019

Accepted:

10.09.2019

Online published:

30.09.2019

Correspondence:

Adnan Ayaz

E-mail:

adnanayaz@comu.edu.tr

CCopyright 2019 by Aquatic

Sciences and Engineering

Available online at

https://dergipark.org.tr/ase

\begin{abstract}
In this study, the aim was to investigate the seasonal variations in the selectivity of striped red mullet (Mullus surmuletus L., 1758) captured by gill nets during the year in the north Aegean Sea. Fisheries' operations were carried out between March 2008 and August 2009. Gill nets with 18, 20, and $22 \mathrm{~mm}$ mesh sizes were used in the trials. These nets are widely used in the region. The SELECT method was used to determine the selectivity of gill nets. The deviances from the SELECT method revealed that lognormal models gave the best fits for all seasons. As a result of the calculations made according to the lognormal model, the modal lengths of the gill nets were calculated as the shortest in the spring season and the longest in the summer. The spread values of the selectivity curves of the experimental gill nets were determined the lowest in the winter season and the highest in the summer season. As a result of selectivity analysis, the differences between the spring and summer season modal lengths of the nets were calculated as $1.5 \mathrm{~cm}, 1.65 \mathrm{~cm}$, and $1.82 \mathrm{~cm}$ for the nets with $18 \mathrm{~mm}, 20 \mathrm{~mm}$, and $22 \mathrm{~mm}$ mesh sizes, respectively. The study results showed that the fishing season was important in gill nets selectivity.
\end{abstract}

Keywords: Seasons, gill net, selectivity, SELECT method, Aegean Sea

\section{INTRODUCTION}

In terms of fishery management, to determine the selectivity of the mesh size of the fishing gear is extremely important knowledge (Millar and Holst, 1997). Fishery management based on mesh selectivity is implemented in gill net fisheries best. It has been reported that the mesh size, body shape, fish size, hanging ratio, the thickness, flexibility, and the visibility of the netting twine, fish behaviour affect the selectivity of gill nets (Clark, 1960; Hamley, 1975). As the most important factor that affects gill net selectivity is the mesh size (Von Brandt, 1975), the studies on this subject are more focused on this factor.

The body shape of the fish varies according to the feeding condition and the breeding season. Before breeding, fish are fed and fat in their habitat. When the breeding season begins after this feeding period, the body consumes the en- ergy for the development of the gonads. Due to this situation, gill net selectivity may show significant changes due to feeding and reproduction in the body of the fish. Qeirrolo and Flores (2016) and Moth-Poulsen (2003) found that seasonal changes are important in selectivity. The effect of fish body shape on selectivity has also been studied in several studies, but seasonal changes have not been studied (Carol and Garcia-Berthou, 2007; Reis and Pawson, 1999).

Reis and Pawson (1999) said that gill nets can be said to be girth-specific fishing gear rather than species-specific fishing gear. Before the fish enter the spawning period, they are highly fed, their condition factor is quite high, and the fish are fat before the spawning. When the breeding season begins, they consume a lot of energy to develop their gonads using this condition. Body circumference may increase further due to the development of gonads according to the fish species. 
Due to the increase in the circumference of the fish, the average length of fish caught in a net during the spawning season may be smaller than the average length of fish caught in the same net outside the spawning season. After reproduction, discharges of fish gonads and the decreasing condition factor of fish due to the consumption of energy to develop the gonads in spawning season cause the girth and length of the fish to be reduced. In this case, unlike the breeding season, the net with the same feature may catch the larger mean fish length than one in the breeding season.

The Striped red mullet is a major economic target species of Aegean Sea demersal fisheries (Arslan \& Işmen, 2013; Torcu-Koç, Erdoğan, Üstün \& Joksimoviç, 2015). Especially in the Aegean sea, this species is captured by fishermen throughout the year. In this study, it is aimed to investigate the changes in seasonal selectivity of striped red mullet (Mullus surmuletus L., 1758)) in the gill nets that are commonly used in the northern Aegean Sea.

\section{MATERIAL AND METHODS}

This study was carried out between March 2008 and August 2009 in the commercial fishing areas on the coast of the North Aegean Sea (Figure 1).

In the trials, nine different gill nets with three mesh sizes $(18,20$ and $22 \mathrm{~mm}$ ) and three different hanging ratios $(E=0.4,0.5$ and 0.6$)$ were used. Each of the nets used in the study had a twine thickness of $210 \mathrm{~d} / 2$, a height of 40 meshes and a length of $80 \mathrm{~m}(E=0.4), 100$ $m(E=0.5)$, and $120 m(E=0.6)$ according to the hanging ratios. Other than the hanging ratios and mesh sizes, all other features and specifications of the gill nets were identical. The nets were riggedin this way since a study on the effects of different hanging ratios on gill net selectivity was also conducted at the same time.

Fifty-nine fishing operations were carried out in total, including nineteen in summer, fifteen in autumn, six in winter, and nineteen in spring. Gill nets were deployed three hours before sunset and were removed from the sea at sunset. Similarly, the nets were set up two hours before sunrise and hauled from the sea an hour after sunrise. After the operation, the weights of fish were taken on scales having $0.01 \mathrm{~g}$ sensitivity and the total lengths (TL) of the fish were measured by millimetric measurement board.

Since there are three nets with different hanging ratios for the same mesh size, the data of striped mullets belonging to these nets were combined and used in selectivity analysis. PASGEAR software (version 2.10) was used in selectivity estimations (Kolding and Skålevik, 2011). This program uses the SELECT (Share Each Length's Catch Total) method, which contains five different models (Normal Location, Normal Scace, Log-normal, Gamma and $\mathrm{Bi}$-modal) in the selectivity estimates of the gill nets (Millar, 1992; Millar and Holts, 1997; Millar and Frayer, 1999). The SELECT model is explained by the following equation

$\mathrm{n}_{l j} \approx \operatorname{Pois}\left(p_{j} \lambda, r_{j}(1)\right)$,

where $\mathrm{n}_{l j}$ is the number of fish of length / caught in mesh size $j, p_{j}$ is the fishing intensity, $\lambda$, reflects the abundance of the length class $I, r(I)$ denotes the retention probability of length $/$ fish in the j'th mesh size.

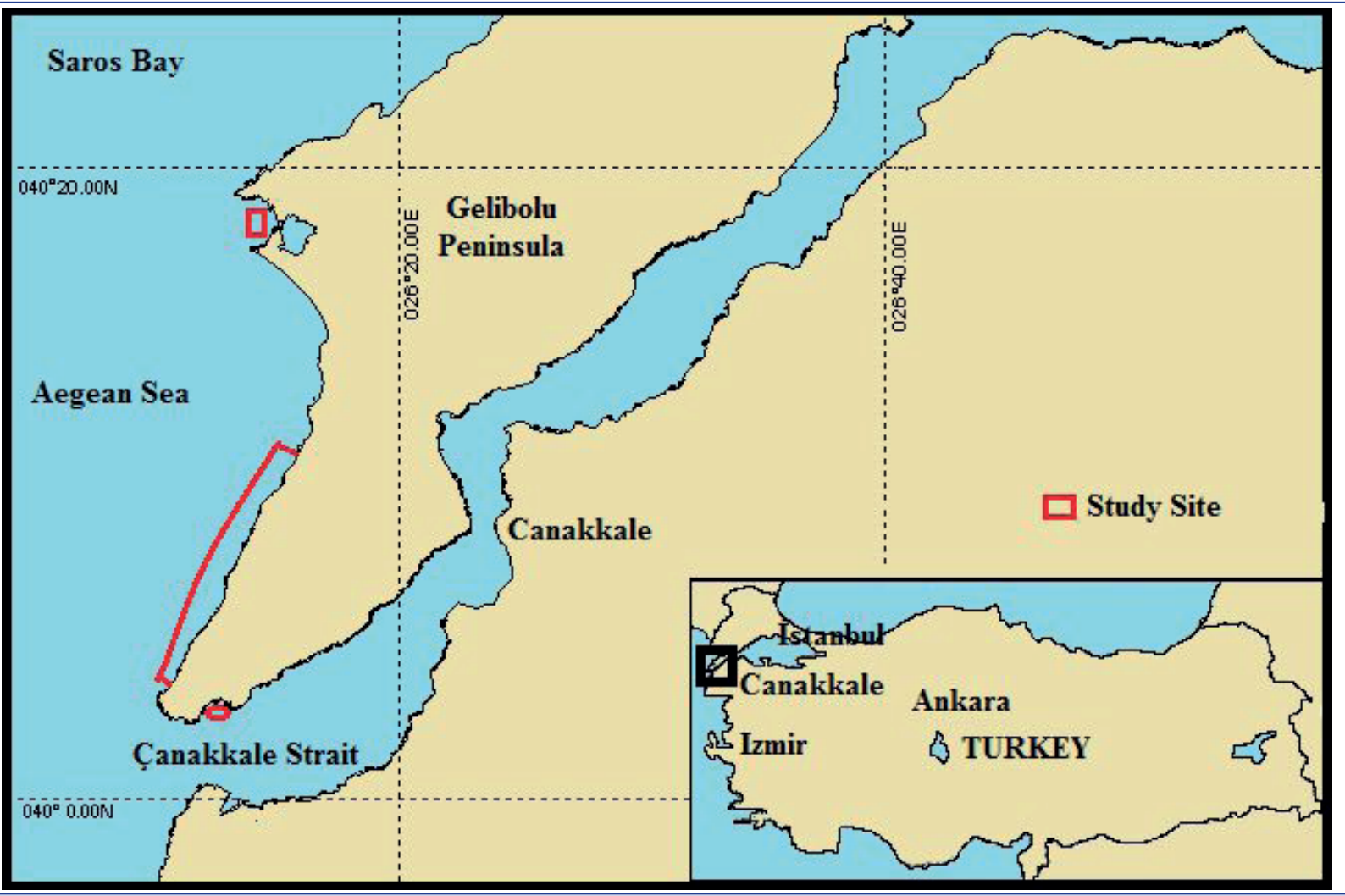

Figure 1. Study area. 
The log likelihood of the model is as:

$\sum_{l} \sum_{j}\left\{n_{l} \log \left[p_{j} \lambda_{l} r_{j}(l)\right]-p_{j} \lambda_{l} r_{j}(l)\right\}$

The equations for each of the models are as such:

$\exp \left(-\frac{\left(L-k \cdot m_{j}\right)^{2}}{2 \sigma^{2}}\right)$

proportional to mesh size,

$\exp \left(-\frac{\left(L-k_{1} \cdot m_{j}\right)^{2}}{2 k_{2}^{2} \cdot m_{j}^{2}}\right)_{\text {for normal scale shift, }}$

$\frac{1}{L} \exp \left(\mu+\log \left(\frac{m_{j}}{m_{1}}\right)-\frac{\sigma^{2}}{2}-\frac{\left(\log (L)-\mu-\log \left(\frac{m_{j}}{m_{1}}\right)\right)^{2}}{2 \sigma^{2}}\right)_{\text {for }}$

log-normal,

$\left(\frac{L}{(\alpha-1) \cdot k \cdot m_{j}}\right)^{\alpha-1} \exp \left(\alpha-1-\frac{L}{k \cdot m_{j}}\right)$ for gamma, and

$\exp \left(-\frac{\left(L-k_{1} \cdot m_{j}\right)^{2}}{2 k_{2}^{2} \cdot m_{j}^{2}}\right)+c \cdot \exp \left(-\frac{\left(L-k_{3} \cdot m_{j}\right)^{2}}{2 k_{4}^{2} \cdot m_{j}^{2}}\right)_{\mathrm{fo}}$

where $L$ is the total length in $\mathrm{cm}, m_{1}$ is the smallest mesh size, $m_{j}$ is the mesh size $j, \mu$ is the mean size (length) of fish caught, $\sigma$ is the standard deviation of the size of fish, and $k$ is a constant. The decision on the most appropriate model fitting the data was evaluated by comparing the deviances of each model and by examining the residual plots.
Size distributions of fish caught in nets for all seasons are compared by using Kolmogorov-Smirnov Test. Before comparison with this test, the data of all the fish caught in the test nets for each season were combined. Comparisons with the Kolmogorov-Simirnov test were performed after this procedure. The nets with the same mesh size were not compared for different seasons.

\section{RESULTS AND DISCUSSION}

In the trials, a total of 1359 individual striped red mullet were captured by gill nets, including 263 in summer, 331 in autumn, 279 in winter, and 518 in spring. In the study, the minimum, maximum, and mean length and weight of the fish caught in the nets according to the seasons are given in Table 1. The total length frequency distributions of the catches according to the same mesh size with different seasons are displayed in Figure 2.

In the comparison of the deviances of the models, the lognormal model gave the best fit for all seasons (Table 2). Selectivity curves obtained from the SELECT method with the lognormal model of striped red mullet caught with gill nets of 18, 20, and $22 \mathrm{~mm}$ mesh sizes and seasons are presented in Figure 3.

The model lengths and spread values of the nets according to the seasons are given in Table 3.

The determined modal lengths of the different mesh sizes for red mullet were found to be lowest in the spring season and highest in the summer season. The spread value is the lowest in the winter and highest in the summer. For the gill nets with 18,20, and $22 \mathrm{~mm}$ mesh sizes, the selectivity ranges were $14.48-19.22 \mathrm{~cm}$, $16.1-21.36 \mathrm{~cm}$, and $17.71-23.49 \mathrm{~cm}$ for the spring season, and $15.55-21.15 \mathrm{~cm}, 17.27-23.49 \mathrm{~cm}$, and $19-25.84 \mathrm{~cm}$, respectively. As a result of selectivity analysis, the differences between the spring and summer season modal lengths of the nets were calculated as $1.5 \mathrm{~cm}, 1.65 \mathrm{~cm}$, and $1.82 \mathrm{~cm}$ for the nets with $18 \mathrm{~mm}, 20$ $\mathrm{mm}$, and $22 \mathrm{~mm}$ mesh sizes, respectively.

Table 1. The minimum, maximum and mean length and weight of the fish caught in the nets according to the seasons.

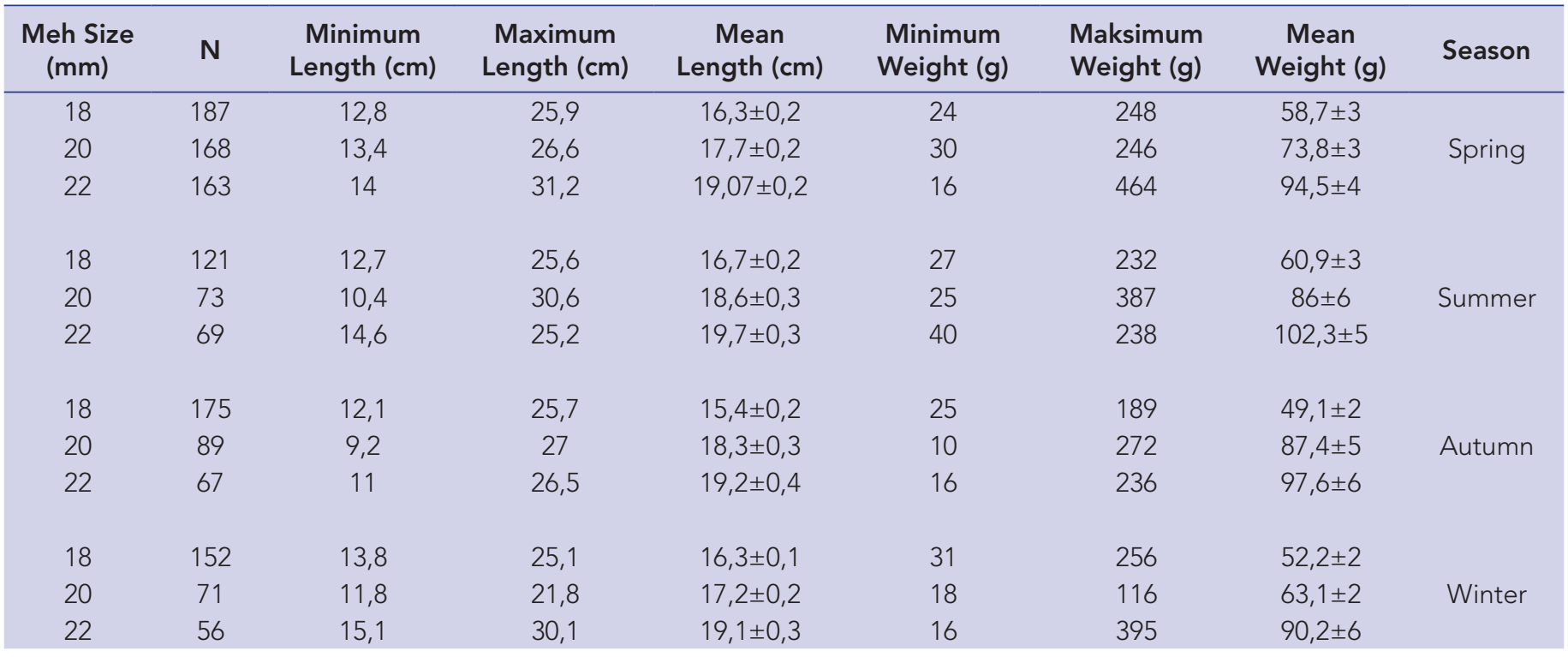




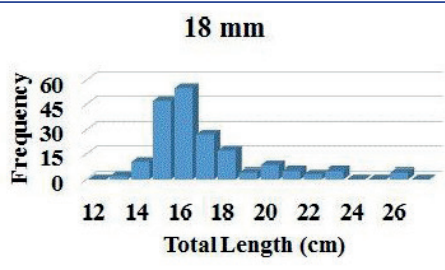

$18 \mathrm{~mm}$
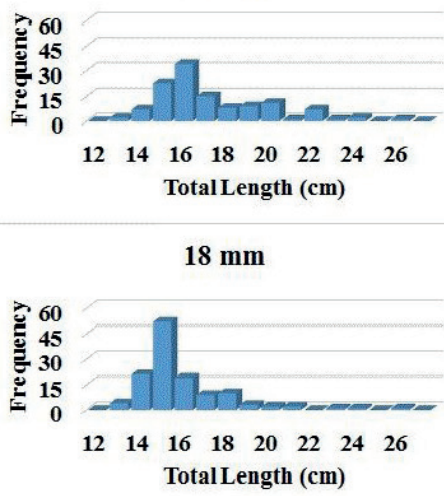

$18 \mathrm{~mm}$

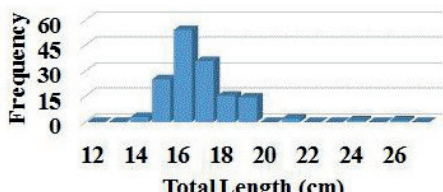

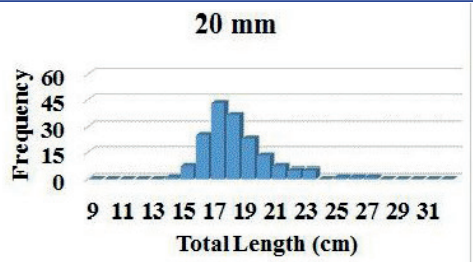

$20 \mathrm{~mm}$
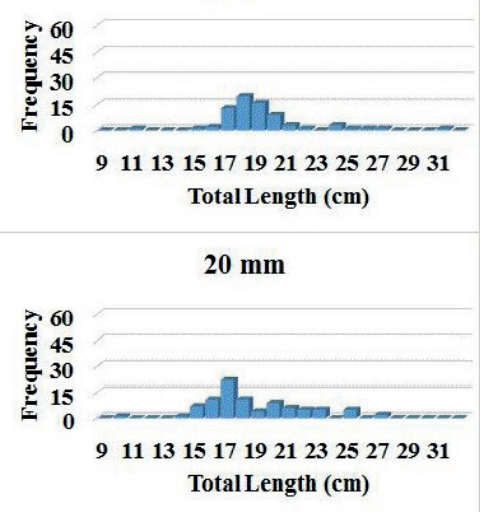

$20 \mathrm{~mm}$

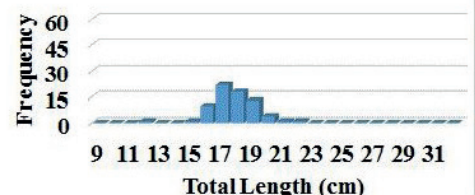

$22 \mathrm{~mm}$

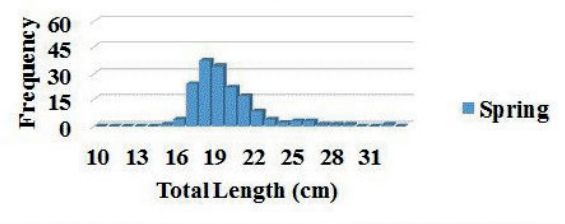

$22 \mathrm{~mm}$

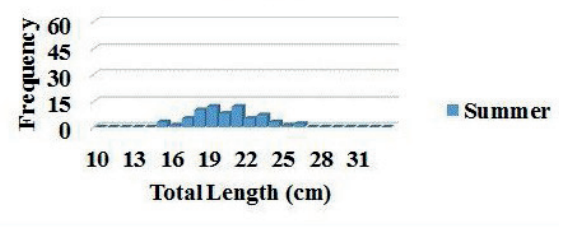

$22 \mathrm{~mm}$

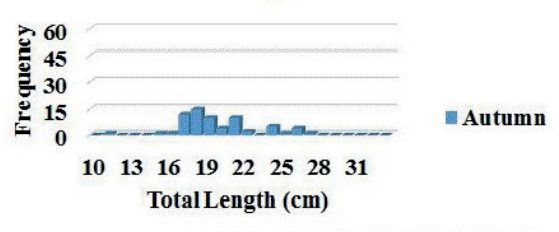

$22 \mathrm{~mm}$

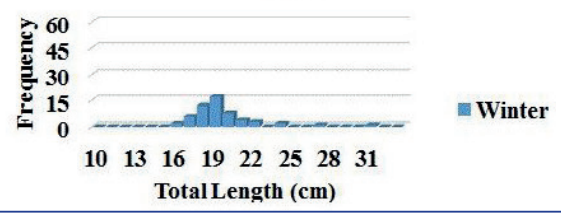

Figure 2. The total length frequency distributions of the catches according to same mesh size with different seasons.

Table 2. Selectivity model parameters according to seasons.

\begin{tabular}{|c|c|c|c|c|c|}
\hline Model & Parameters & $\begin{array}{c}\text { Modal } \\
\text { Deviance }\end{array}$ & P-Value & $\begin{array}{l}\text { Degrees of } \\
\text { Freadom (Df) }\end{array}$ & Season \\
\hline Normal location & $(k, \sigma)=(9.395,2.697)$ & 113.534 & 0.0000001 & 39 & \multirow{5}{*}{ Spring } \\
\hline Normal scale & $(k 1, k 2)=(9.609,1.510)$ & 137.153 & 0.0000001 & 39 & \\
\hline Lognormal & $(\mu 1, \sigma)=(2.843,0.136)$ & 99.088 & 0.0000001 & 39 & \\
\hline Gamma & $(k, a)=(0.191,50.356)$ & 111.676 & 0.0000001 & 39 & \\
\hline Bi-modal & $(k 1, k 2, k 3, k 4, w)=$ No Fit & & & & \\
\hline Normal location & $(k, \sigma)=(10.248,2.697)$ & 78.531 & 0.000081 & 37 & \multirow{5}{*}{ Summer } \\
\hline Normal scale & $(k 1, k 2)=(10.533,1.542)$ & 85.788 & 0.00001 & 37 & \\
\hline Lognormal & $(\mu 1, \sigma)=(2.931,0.147)$ & 73.201 & 0.00036 & 37 & \\
\hline Gamma & $(k, a)=(0.221,47.588)$ & 76.553 & 0.00014 & 37 & \\
\hline Bi-modal & $(k 1, k 2, k 3, k 4, w)=$ No Fit & & & & \\
\hline Normal location & $(k, \sigma)=(9.783,2.738)$ & 92.129 & 0.000001 & 36 & \multirow{5}{*}{ Autumn } \\
\hline Normal scale & $(k 1, k 2)=(10.029,1.382)$ & 98.850 & 0.000001 & 36 & \\
\hline Lognormal & $(\mu 1, \sigma)=(2.875,0.138)$ & 84.142 & 0.000010 & 36 & \\
\hline Gamma & $(k, a)=(0.186,53.638)$ & 87.718 & 0.000003 & 36 & \\
\hline Bi-modal & $(k 1, k 2, k 3, k 4, w)=$ No Fit & & & & \\
\hline Normal location & $(k, \sigma)=(9.776,2.093)$ & 43.773 & 0.016 & 26 & \multirow{5}{*}{ Winter } \\
\hline Normal scale & $(\mathrm{k} 1, \mathrm{k} 2)=(9.45,1.063)$ & 50.864 & 0.002 & 26 & \\
\hline Lognormal & $(\mu 1, \sigma)=(2.88,0.108)$ & 37.959 & 0.061 & 26 & \\
\hline Gamma & $(k, a)=(0.114,87.055)$ & 41.481 & 0.028 & 26 & \\
\hline Bi-modal & $(k 1, k 2, k 3, k 4, w)=$ No Fit & & & & \\
\hline
\end{tabular}




\section{$18 \mathrm{~mm}$}
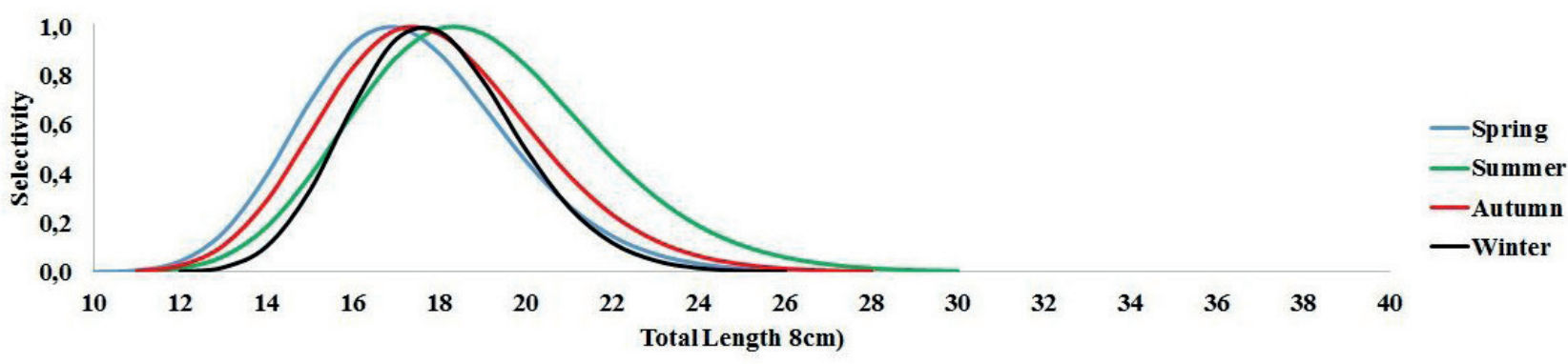

$20 \mathrm{~mm}$

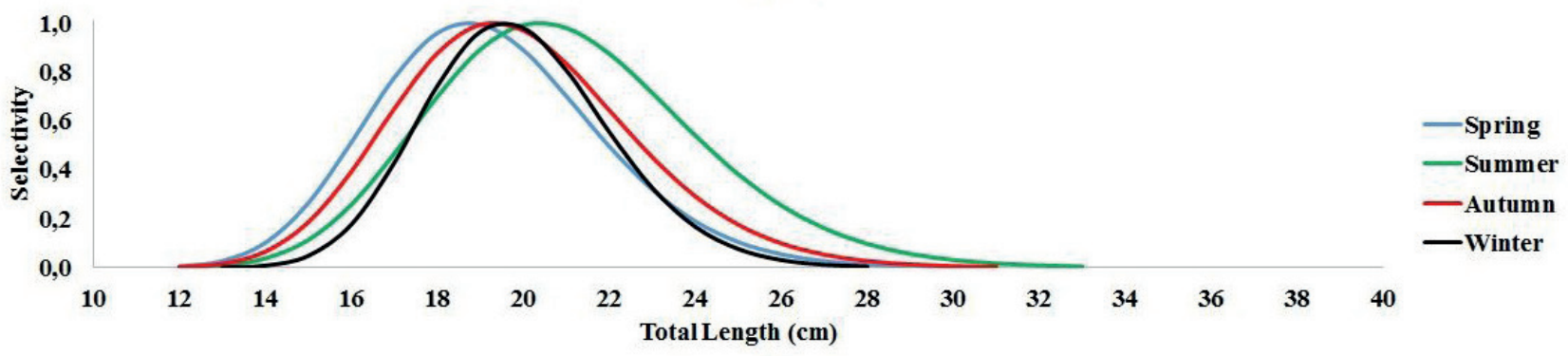

$22 \mathrm{~mm}$

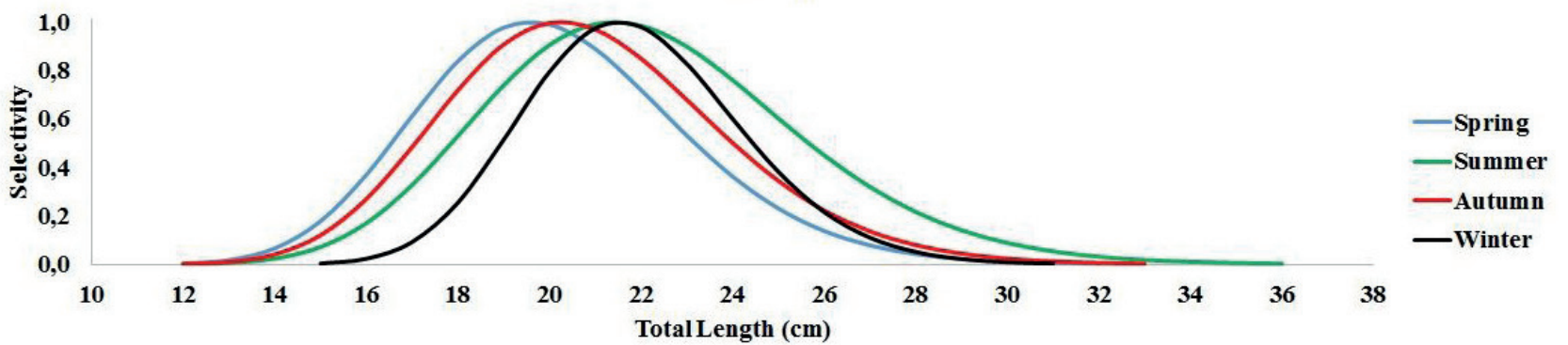

Figure 3. The comparison of the selectivity curve according to the seasons.

Table 3. The model lengths and spread values of the nets accordinto the seasons.

\begin{tabular}{|c|c|c|c|c|}
\hline Meh Size (mm) & Modal Length (cm) & Spread Value (cm) & Selectivity Range (cm) & Season \\
\hline 18 & 16.85 & 2.37 & $14.48-19.22$ & \multirow[b]{2}{*}{ Spring } \\
\hline 20 & 18.73 & 2.63 & $16.1-21.36$ & \\
\hline 18 & 18.35 & 2.8 & $15.55-21.15$ & \multirow[b]{2}{*}{ Summer } \\
\hline 20 & 20.38 & 3.11 & $17.27-23.49$ & \\
\hline 18 & 17.39 & 2.48 & $14.91-19.87$ & \multirow{3}{*}{ Autumn } \\
\hline 20 & 19.32 & 2.76 & $16.56-22.08$ & \\
\hline 22 & 21.26 & 3.03 & $18.23-24.29$ & \\
\hline
\end{tabular}


A statistically significant difference was found between the size distributions of fish caught in the nets for all seasons $(P<0.05)$.

It was observed that the model sizes calculated from the fish caught in the nets according to the seasons are at the lowest value in the spring season, and the highest value is calculated in the summer season. illhan et al. (2009) stated that the reproduction of striped red mullet occurred in the spring season in their study in İzmir Bay. Torcu-Koç et al. (2015) found that the breeding season of this fish in Edremit Bay, which is close to the study region, was in April-September and that the breeding peaked in July. Arslan and issmen (2013) reported that the reproduction took place in April and May in the Saroz Bay. According to previous studies, it has been reported that the breeding season of this fish species occurs mostly in April and May and may be seen in some regions in summer (Torcu-Koç et al., 2015). As a result of the experiments, the modal lengths of the nets calculated according to the seasons are the smallest in the spring season and can be explained by the increase in the body girth of the fish due to reproduction. The fact that most of this fish species completed the breeding season in summer caused the fish to fall in average body girth. This situation caused the modal lengths of the nets to increase compared to other seasons. According to these results, the high spread value indicates that reproduction is at the beginning of summer. At the beginning of the summer season, the presence of fish that have not yet completed their reproduction has increased the length variance of the fish caught in the nets. This may have caused the spread value calculated for the summer season to be high.

The average total lengths of the fish caught in the experimental nets were determined to be the lowest in winter and the highest in summer. In the experiment, it was expected that it would be the lowest in spring because of this gonad growth. In the winter season, only fishing operations were carried out at one station in February due to weather conditions. This situation may have caused the average total length of fish to be low in winter.

Qeirrolo and Flores (2016), Moth-Poulsen (2003) found that seasonal changes are important in selectivity. In some studies, although the difference in seasonal selectivity is not significant, in our study, selectivity differences between seasons were found to be particularly significant in summer $(P<0.05)$. Study results are similar to Qeirrolo and Flores (2016), Moth-Poulsen (2003).

In recent studies, length at first maturity of this fish for female and males were determined $13.7 \mathrm{~cm}$ and $13.2 \mathrm{~cm}$ respectively in the Saroz Bay (Arslan and İşmen, 2013), $11.9 \mathrm{~cm}$ for females and males on the Mediterranean coast of Egypt (Amin, Madkour, Abu El-Regal \& Moustafa, 2016), and $16.6 \mathrm{~cm}$ for all individuals in Canary Islands (Pajuelo et al., 1997). When the results of the study were examined, it was seen that the selectivity ranges of experimental nets were larger than the length at first maturity. However, when smaller than $18 \mathrm{~mm}$ mesh sizes (17, $16 \mathrm{~mm}$ and smaller) were used, it was observed that it could give rise to dangerous results for its fish stocks.

\section{CONCLUSION}

Study results showed that seasonal changes are important in selectivity. But further studies are needed. If other studies have similar results, seasonal changes should be taken into account in management arrangements related to gill net selectivity.

Conflict of Interests: The author declares that there are no conflicts of interest

Financial Disclosure: This study was funded by TUBITAK with project number 106 Y021

\section{REFERENCES}

Amin, A. M., Madkour, F. F., Abu El-Regal, M. A. \& Moustafa, A.A. (2016). Reproductive biology of Mullus surmuletus (Linnaeus, 1758) from the Egyptian Mediterranean Sea (Port Said). International Journal of Environmental Science and Engineering, 7, 1-10.

Arslan, M. \& Işmen, A. (2013). Age, growth and reproduction of Mullus surmuletus (Linnaeus, 1758) in Saros Bay (Northern Aegean Sea). Journal of Black Sea/Mediterranean Environment, 19(2): 217-233.

Clarke, J. R. (1960). Report on selectivity of fishing gear. International Commission for the Northwest Atlantic Fisheries Special Publication, 2, 27-36.

Carol, J. \& Garcia-Berthou, E. (2007). Gillnet selectivity and its relationship with body shape for eight freshwater fish species. Journal of Applied Ichthyology, 23, 654-660. [CrossRef]

Hamley, J. M. (1975). Review of gillnet selectivity. Journal of the Fisheries Research Board of Canada, 32, 1943-1969. [CrossRef]

Illhan, D. U., Akalın, S., Özaydın, O., Tosunoğlu, Z. \& Gurbet, R. (2009). Growth and reproduction of striped red mullet (Mullus surmuletus L., 1758) in Izmir Bay (In Turkish). Ege Journal of Fisheries and Aquatic Sciences, 1, 01-05.

Kolding, J. \& Skålevik, Å. (2011) PasGear 2. A database package for experimental or artisanal fishery data. Version 2.5. available at http:// www.imr.no/forskning/utviklingssamarbeid/eaf_nansen_programmet /pasgear_2/en

Millar, R. B. (1992). Estimating the Size-Selectivity of Fishing Gear by Conditioning on the Total Catch. Journal of the American Statistical Association, 87, 962-968. [CrossRef]

Millar, R. B. \& Holst, R. (1997). Estimation of gillnet and hook selectivity using log-linear models. ICES Journal of Marine Science, 54, 471477. [CrossRef]

Millar, R. B. \& Fryer, R. J. (1999). Estimating the size-selection curves of towed gears, traps, nets and hooks. Reviews in Fish Biology and Fisheries, 9, 89-116. [CrossRef]

Moth-Poulsen, T. (2003). Seasonal variations in selectivity of plaice trammel nets. Fisheries Research, 61, 87-94. [CrossRef]

Qeirrolo, D. \& Flores, A. (2016). Seasonal variability of gillnet selectivity in Chilean hake Merluccius gayi gayi (Guichenot, 1848). [CrossRef]

Pajuelo J. G. Lorenzo, J. M. Ramos A. G. \& Méndez-Villamil, M. (1997). Biology of the red mullet Mullus surmuletus (Mullidae) off the Canary Islands, Central-East Atlantic. South African Journal of Marine Science, 18(1), 265-272. [CrossRef]

Reis, E. G. \& Pawson, M. G. (1999). Fish morphology and estimating selectivity by gillnets. Fisheries Research, 39, 263-273. [CrossRef]

Torcu-Koç, H. Erdoğan, Z. Üstün, F. \& Joksimovic, A. (2015). Some biological parameters of the striped red mullet (Mullus surmuletus L.) from the Bay of Edremit (Northern Aegean Sea, Turkey). Acta Adriatica, 56(2), 223-232.

Von Brandt, A. (1975). Enmeshing nets: gillnets and entangling nets - the theory of their efficiency. European Inland Fisheries Advisory Commission Technical Paper, 23(Supplement 1), 1, 96-116. 